\title{
REVISITING EMU'S STABILITY PACT: A PRAGMATIC WAY FORWARD
}

\author{
MARCO BUTI \\ European Commission \\ SYLVESTER EIJFFINGER \\ CentER for Economic Research, Tilburg University, and CEPR \\ DANIELE FRANCO \\ Banca d'Italia ${ }^{1}$
}

\begin{abstract}
The Stability and Growth Pact is under fire. Some countries are meeting major problems in sticking to the rules. Proposals to reform the Pact or ditch it altogether abound. The alleged weaknesses of the Pact tend to reflect trade-offs typical of supra-national arrangements. This aspect has to be factored in when considering reforms of the current fiscal rules: there is no miracle solution. EMU without rules would be an interesting experiment, but a risky policy option. Given the existing degree of political integration in EMU, internal adjustment rather than attempting to redesign the rules from scratch appears a more suitable way forward. Redefining the medium-term budgetary target, improving transparency, tackling the pro-cyclical fiscal bias in good times, moving towards non-partisan application of the rules, and improving transparency in the data can achieve both stronger discipline and higher flexibility.
\end{abstract}

\section{INTRODUCTION}

The Stability and Growth Pact (SGP) is one of the pillars of Economic and Monetary Union (EMU). It is a disciplinary device aiming at ensuring sound budgetary balances and low public debts.

While widely regarded as a major innovation (Artis, 2002), the Pact has been the subject of a heated controversy ever since its inception. It has been extensively criticized by academics and opinionmakers. Proposals for radical changes have been put forward and even the suppression of the Pact has been considered. This debate has accelerated in 2002 under the influence of public finance developments in a number of euro-area countries which have called into question its effectiveness and wisdom.

\footnotetext{
${ }^{1}$ This paper is based on a longer study (see Buti et al., 2003) The views expressed are those of the authors and should not be attributed to the institutions to which they are affiliated. The authors thank Ivo Arnold, Jakob de Haan, Lex Hoogduin, Harry Huizinga, Lucio Pench, and Ignazio Visco for their valuable comments on this paper or on the longer study.
} 
In a way, these policy problems and debates are related to the success of EMU rules in curbing deficits. When the public finances in a number of EU countries appeared to be on an unsustainable path, the benefits of lower deficits were evident. Fiscal discipline was recognized as a pre-condition to lower interest rates and to use fiscal policy for cyclical stabilization (Buti et al., 1998). The arbitrary nature of the 3 per cent deficit limit appeared acceptable in view of the need to enforce fiscal discipline. Now that deficits have been lowered, the issue of the proper balance between fiscal discipline and other targets has come to the fore.

Our analysis and proposals take as given the current preferences for political integration. This implies that fiscal policies stay decentralized and coordination continues to be mainly of the negative type (i.e. surveillance), reflecting an enduring mistrust among euro-area members. Obviously, if the euro increases the taste for political integration towards a fully fledged federal structure, a different public finance system could be devised.

The outline of the paper is as follows. Section II analyses how the SGP qualifies against ideal standards to be met when designing a fiscal rule. Section III examines the main proposals put forward to replace or radically revise the Pact. In section IV, we make some suggestions for improving the functioning of the SGP which can be implemented within the current institutional setting. Section V concludes.

\section{FISCAL RULES FOR A MONETARY UNION}

The role of fiscal institutions and procedures in shaping budgetary outcomes has been increasingly recognized. While 'good rules' do not necessarily entail 'good policies', inadequate budgetary institutions and procedures may contribute to a lack of fiscal discipline.

In a previous paper (Buti et al., 2003), we have analysed the 'quality' of EU fiscal rules in terms of the criteria identified by Kopits and Symansky (1998) and Inman (1996) for the design, implementation, and enforcement of a fiscal rule. A good fiscal rule should be well designed (clearly defined, simple, transparent, consistent, and flexible), allow effective implementation (by entailing ex-ante and ex-post compliance and efficient monitoring), and be enforceable (in terms of decision, amendment, and sanctions). Our conclusion is that the SGP has strong points, in particular as regards simplicity and monitoring, and weak points, particularly concerning enforcement. However, in order to pass a judgement, one has to consider that the criteria discussed in the literature were devised for assessing the quality of domestic fiscal rules. With EMU, for the first time, fiscal rules had to be devised in a multinational context.

EMU fiscal rules reflect the interaction between the multinational nature of EMU and the lack of a political authority of federal rank (Balassone and Franco, 2001). This has important implications. First, national sovereignty and subsidiarity concerns had to be respected. This implies that rules are to be as neutral as possible vis-à-vis the countries' social preferences, which are quite heterogeneous in the EU. This prevented, for instance, the adoption of rules which entail a choice of the role and size of the public sector in the economy.

Second, in a supra-national context, ex-postcompliance is important, given the higher risks of moral hazard and the higher difficulty in monitoring $e x$ ante policy announcements. Reputational effects, such as those of 'early warnings' and excessive deficit positions, are also important, while the implementation of formal sanctions remains under question because of the political difficulty of imposing them on sovereign countries.

Third, the multinational character influences the trade-offs between the various criteria in complex ways. Take the trade-off between simplicity and flexibility. On the one hand, there may be a preference for simplicity over flexibility to allow peer pressure and central monitoring and prevent moral hazard. On the other hand, a multiplicity of countries increases heterogeneity and dispersion of preferences, with the consequence that a one-size-fits-all fiscal rule is likely to be sub-optimal.

The supra-national nature of the EU fiscal rules has to be kept in mind when considering their possible reform. 


\section{REVISITING THE SGP: MAIN PROPOSALS}

According to its critics, the Pact has several shortcomings: it reduces budgetary flexibility, works asymmetrically, is too uniform, does not sanction politically motivated fiscal policies, discourages public investment, disregards the area fiscal stance, and disregards long-term sustainability. In the end, the Pact would hamper economic growth.

In this context, several proposals have been put forward for replacing or modifying the Pact. One way or another, all the proposals draw on one or more of the above criticisms. They can be grouped in three categories: reforms of national budgetary procedures; coordination at the euro-area level; and shift to different numerical rules.

\section{(i) Reforms of National Procedures and Institutions}

The first-best strategy in ensuring sound fiscal policies would be that of dealing directly with the factors leading to excessive deficits at the national level. This would avoid relying on numerical parameters, which are necessarily arbitrary. Fiscal policy soundness would be ensured either by market discipline or by procedures assuring fiscal responsibility at the national level.

This strategy answers the criticism concerning the lack of budgetary flexibility. Budgetary flexibility is limited, especially in the transition to broadly balanced budgets: in a situation of subdued growth, such transition requires pro-cyclical policies that may worsen the cyclical conditions. Moreover, procyclical policies cannot be excluded in the future if the room for manoeuvre envisaged by the SGP turns out to be insufficient to cope with large-scale recessions and adverse shocks.

Two sets of proposals come under this heading.

\section{Procedural reforms}

Procedural reforms impose changes on the rules concerning the presentation, adoption, and execution of government budgets. Hierarchical procedures are more conducive to fiscal discipline than collegial procedures. At the national level, hierarchical rules attribute strong power to the treasury minister to overrule spending ministers during the intra-governmental preparation of the budget, and limit the ability of the parliament to amend the government's budget proposals.

Replacing the numerical limits with procedures ensuring sound budgetary positions would raise two problems. First, there is still a need for transparent and rapid criteria for selecting new entrants to the euro area. Second, the adoption of harmonized budgetary procedures would raise problems from the point of view of national sovereignty and might conflict with national institutions and traditions. The alternative solution - country-specific procedures approved at EU level — would also be problematic. The ex-ante effectiveness of these procedures would be very difficult to evaluate. Moreover, if they did not prove effective in constraining deficits, the attribution of responsibility would be difficult, as national governments might argue that they have implemented the agreed procedures.

In the end, while effective national budgetary procedures are important in ensuring sound fiscal policies at the national level, they do not appear at present to be a viable solution at the EU level. However, some procedural rules (such as common accounting conventions or the adoption of stability programmes) are called upon to ensure compliance with the budget constraints.

\section{Institutional reforms}

The proposal to assign to a newly created independent body the role of setting fiscal targets draws on the experience of central banks running monetary policy. The independent body would aim at delivering both long-term stability/sustainability and flexible short-term stabilization. Setting up such institutions would imply a principal-agent solution for the fiscal discipline problem.

Wyplosz (2002) suggests allocating to a Fiscal Policy Committee (FPC) the responsibility for setting the budget balance on the basis of a debtsustainability constraint defined over a number of years. The constraint would either be expressed as an obligation to achieve budget balance over the cycle or to reduce or stabilize the debt ratio over a given horizon. The FPC would be accountable to parliament. In order to replace the existing EU rules, each country would have to adopt a statute for the 
new body compatible with agreed norms. The FPC's statute would indicate its goals and powers, and the conditions under which deviations from its goals are allowed.

While intellectually appealing, this proposal runs into serious feasibility problems. Fiscal policy is - differently from monetary policy-at the heart of the political decision-making process. The separation between setting a target for the budget balance (to be entrusted to the FPC) and the allocative and distributive functions (to remain in the responsibility of government and parliament) may turn out to be difficult. Decisions about the budget balance affect the composition of expenditure and revenues. Politically, it is hard to conceive that a minister of finance would delegate part of fiscal policy authority to an independent agency.

\section{(ii) Fiscal Policy Coordination at the Euro-area Level}

A second category of reform proposals envisages fiscal coordination at the euro-area level. In a currency union, only the aggregate fiscal stance is relevant for the policy mix at the euro-area level and, as such, enters the reaction function of the central bank. Hence, it is suggested that a target is set for the euro area as a whole and then shared between member countries.

These solutions respond to the allegation that the SGP disregards the aggregate fiscal stance. Under the Pact, each country is responsible for national fiscal policies. However, the aggregation of nationally determined fiscal policies may not result in an optimal fiscal stance at the euro-area level.

Fiscal coordination can be achieved either via community-level decisions indicating the desirable budget balance of each country or a market-based allocation of national deficit shares of the total euro-area deficit.

\section{Community allocation of deficit shares}

A proposal for a coordination mechanism in the budgetary domain was submitted by the French Finance Minister at the informal Ecofin Council in April 1999. The proposal stressed that the aggregate policy stance at the EMU level must be examined on the basis of an aggregate stability programme. It pointed out that the objective of achiev- ing an adequate policy stance for EMU as a whole should be taken into account when examining the national stability programmes.

A natural implication of this is that the 3 per cent of GDP deficit criterion would only apply to the average deficit for the euro area. Member states would be permitted to overshoot the 3 per cent deficit ceiling if there were other countries with deficits below that value. Since the amplitude of cyclical fluctuations is much smaller for the Eurozone as a whole, the targets needed to prevent an overshooting of the aggregate deficit ceiling would be less stringent than those necessary for each member state individually.

However, in the present institutional set-up of EMU, the deficit criterion applies to each member state individually. The Maastricht budgetary rules would thus have to be renegotiated in order to allow this interpretation to be implemented. Bureaucratic allocation of deficit shares would be highly controversial. Moreover, if the norm for budgetary behaviour in EMU is that of relying on automatic stabilizers, the likelihood that the aggregation of the national fiscal stances gives rise to an inappropriate stance at the aggregate level is negligible.

In sum, while a shift to numerical constraints applying to the euro area as a whole is politically infeasible and probably economically undesirable, a move towards a framework which encompasses an assessment of the fiscal stance of the euro area as a whole prior to that of the individual members could be envisaged (Buti and Nava, 2003). However, steps in this direction should not lead to a relaxation of national fiscal responsibility.

\section{Market allocation of deficit permits}

Casella (2001) proposes to use market mechanisms in the allocation of 'deficit shares' in EMU. Having chosen an aggregate target for the Union and an initial distribution of tradable deficit permits, EMU countries could be allowed to trade rights to deficit creation. While this system keeps the aggregate area-wide deficit unchanged, it allows individual member states to deviate from the initial allowances in case of idiosyncratic shocks. If a country is hit by a negative shock, it can use fiscal policy to counteract the shock by buying permits from countries with a surplus. 
The mechanism would minimize the aggregate cost of compliance with the aggregate targets and provide rewards for countries running surpluses in favourable cyclical conditions, thereby tackling the issue of the asymmetric working of the Pact (Buti and Martinot, 2000). It would also reduce the room for political manipulation.

This scheme is subject to three main difficulties. First, efficacy requires that the deficits of the various governments generate the same externality and are thus perfect substitutes. But the risk of triggering a financial crisis is not uniform across governments. Second, the efficiency of the market in permits depends on how competitive it is. This makes the mechanism ill-suited to situations in which the number of governments is small. Finally, there is no easy solution to the problem of determining the initial allotment of permits. The possible criteria (GDP, population, etc.) would produce greatly differing allocations. If the initial demand for permits exceeded the supply, then the countries with an allotment greater than their requirement would enjoy positional rents.

\section{(iii) Alternative Numerical Rules: Factoring in the 'Quality' of Public Finances}

Numerical constraints on domestic fiscal policy in terms of an indicator of overall fiscal performance are more suited to the multinational context of EMU, in which moral-hazard issues are quite relevant, and to the need for rapid results. Compliance to numerical rules is somewhat simpler to evaluate.

Numerical rules can be divided into two groups. The first includes rules of a static nature, concerning the level and composition of the public budget in a specific year. The second includes the rules of more dynamic nature, referring to debt development and fiscal sustainability. The two categories are respectively examined in this section and in section III(iv).

The SGP focuses on the yearly budget balance. However, a growing body of literature points out that the composition of public finances matters as well. The focus on quality has been translated into two proposals for reforming the SGP: shifting from a deficit target to $(a)$ an expenditure target/rule, or moving to $(b)$ the so-called golden rule of deficit financing.

\section{Expenditure rules}

Focus on expenditure has the advantage of controllability because expenditure depends much less than revenue on the business cycle. Expenditure rules can link the annual budgetary process to a multiannual policy framework. They refer to the budgetary items that governments can control and which can be easily defined and monitored. Moreover, they allow stabilizers to work on the revenue side and may prevent expenditure relaxation in upturns.

Ideally, expenditure rules should use a comprehensive definition of public expenditure, including both discretionary items and entitlements, and apply to the different levels of government. They should require both ex-ante and ex-post compliance. Deviations in one year should be compensated in the following years.

The use of expenditure rules in a multinational context, however, appears problematic. First, uniform spending rules would de facto impose homogeneous social preferences on politically heterogeneous countries, while country-specific rules would be difficult to enforce. Second, spending norms do not refer to the fiscal variables which can produce negative externalities. While a rising deficit or debt level in one country can create area-wide problems, a rising expenditure level as such does not have negative repercussions on other countries. Moreover, expenditure rules cannot prevent deficit and debt increases stemming from tax cuts. Therefore, they would have to be complemented by a deficit or debt rule. Third, since no uniform expenditure-toGDP ratio can be prescribed, countries would be required to indicate targets for the expenditure ratio consistent with the desired deficit ratio. Finally, the size of the budget typically reflects the political preferences of the government. A new government may want to renegotiate the commitments of its predecessor.

In sum, while expenditure rules may prove useful at the national level, they are more appropriate as complements rather than substitutes for rules on deficits and debt.

\section{The golden rule}

A number of authors have suggested replacing the SGP by some form of golden rule (Blanchard and Giavazzi, 2003). Borrowing would be allowed to 
finance public investment. As already pointed out by Musgrave (1939), implementing the golden rule requires establishing a dual budget, separating investment spending from current spending.

The golden rule would allow spreading the burden of capital projects over the different generations of taxpayers benefiting from them and would avoid the efficiency loss caused by distortionary taxation if the tax rate fluctuates over time. This would answer some of the criticisms expressed against the SGP. In fact, maintaining budget positions 'close to balance or in surplus' implies that capital expenditure will have to be funded from current revenues, which may imply a disincentive to undertake projects producing deferred benefits. The disincentive is stronger during consolidation periods.

However, there are a number of arguments against the introduction of the golden rule (Balassone and Franco, 2000; Buiter, 2001).

First, the alleged incompatibility between the SGP and a properly defined golden rule is questionable. In order to spread the burden of capital spending over the different generations of taxpayers, the rule would have to refer to net spending. ${ }^{2}$ While commonly agreed estimates of amortization are not available, in developed countries in which infrastructures are partly developed by subjects not included in general government, the level of net investment seems limited and not necessarily inconsistent with the close-to-balance rule of the SGP. ${ }^{3}$

Second, if applied to gross public investment, the golden rule would be an obstacle to deficit and debt reduction. Given the ratio of public investment as a percentage of GDP, the long-run equilibrium level of government debt could be quite high, especially in an environment of low inflation.

Third, singling out public investment from other budget items makes little sense. What is important is overall capital accumulation in both private and public capital. For instance, a well-devised tax reform that, by lowering the tax burden and distortions, leads to higher investment may be preferable to public investment. Moreover, there is no clear evidence in the empirical literature that investment in public infrastructure always leads to significant positive growth effects. Some studies suggest that government investment may be subject to rapidly decreasing returns (see, for example, de la Fuente, 1997). From the standpoint of intergenerational equity, it is not clear that a combination of higher infrastructure investment and higher public debt would necessarily be preferable to lower investment with lower debt. Moreover, a golden rule may distort expenditure decisions in favour of physical assets and against spending on intangibles that can make a relevant contribution to economic growth, for example those increasing human capital.

Finally, the golden rule would make the multilateral surveillance process more complex by providing leeway for opportunistic behaviour, since governments would have an incentive to classify current expenditure as capital spending.

\section{(iv) Alternative Numerical Rules: Focus on Debt Level and Sustainability}

The current EU rules do not focus on the issue of sustainability and disregard the fact that countries are different. This criticism has different nuances. First, the SGP focuses almost exclusively on shortterm objectives for the budget deficit. As such, it provides incentives for creative accounting and one-off measures which blur the transparency of public accounts. Second, the stock of public debt does not enter the SGP and neither do the contingent liabilities of public pension systems. Hence, the Pact treats equally countries with different medium- and long-term prospects and different debt levels. Third, the Pact may prevent countries from implementing policies - such as pension reforms - which improve long-term sustainability and at the price of a shortterm deficit worsening. ${ }^{4}$

Two solutions have been put forward in the literature: the first is to choose a medium-term target that ensures long-term sustainability while taking on board country specificities; the second is to give more weight to the public debt.

\footnotetext{
${ }^{2}$ Indeed, it is only the net addition to public capital that should be financed via borrowing, while the part that covers depreciation should remain tax-financed. See HM Treasury (1998), Kilpatrick (2001), and Blanchard and Giavazzi (2003).

${ }^{3}$ For Germany, see Wendorff (2001).

${ }^{4}$ For a theoretical model, see Razin and Sadka (2002).
} 
From the Maastricht parameters to tax smoothing

As catching-up countries are characterized by higher potential growth and higher inflation (the latter owing to the Balassa-Samuelson effect), they can afford to have higher deficits without endangering the long-term sustainability of public finances. Hence, the 3 per cent of GDP deficit ceiling and the closeto-balance rule are over-restrictive for these countries. Given the higher public-investment needs of less mature economies, the current fiscal rules could harm the catching-up process.

Buiter and Grafe (2003) propose a Permanent Balance Rule which would ensure sustainability and fiscal prudence while taking into account country differences. Their rule is a strong form of tax smoothing: it requires that the inflation-and-realgrowth-adjusted permanent government budget is in balance or surplus. The permanent budget balance is given by the difference between the constant long-run average future values of tax revenue and government spending.

While the rule is theoretically appealing, its applicability appears doubtful (Pench, 2003). First, it requires an estimate of the permanent value of tax and spending, thereby requiring the taking into account of future social and political preferences and the making of assumptions on future growth rates. This would likely violate the criteria of simplicity and enforceability discussed in section II. Second, nominal GDP growth can be higher in catching-up economies but also highly variable. This implies a potential conflict between discipline and stabilization. If a country which maintains a high structural deficit is hit by a shock, the automatic stabilizers may lead to very high deficits. While in principle these deficits are of a cyclical nature, the risk of spiralling debt and interest payments should not be disregarded. This risk is particularly high in accession countries which still suffer from limited creditworthiness and may see capital inflows dry up quickly.

\section{More weight on the public debt}

A way to overcome the uniformity of the Pact is to attribute more importance to public debt. Calmfors and Corsetti (2002) suggest making the deficit ceiling dependent on the stock of debt. The deficit ceiling of 3 per cent of GDP should apply only to countries with a debt ratio in excess of 55 per cent of GDP (see also EEAG, 2003). A higher ceiling would apply to countries with lower debt. For instance, a ceiling of 4 per cent of GDP would be set for countries with a stock of debt between 35 and 45 per cent.

This proposal respects the requirement of simplicity while improving incentives and country differentiation. It would be 'enlargement friendly' as most of the newcomers have a fairly low stock of debt. However, it would require a change in the Treaty. As we argue in the next section, a similar debtdeficit articulation could be obtained through a system of 'rainy-day funds'.

Tackling the issue head on, Pisani-Ferry (2002) suggests giving countries the choice of opting out of the Excessive Deficit Procedure and embracing a Debt Sustainability Pact. ${ }^{5}$ This Pact would allow countries keeping their debts below 50 per cent of GDP and publishing comprehensive fiscal accounts to be exempted from the standard excessive deficit procedure and sanctions. Fiscal accounts would provide estimates of the future impact of budgetary commitments, such as the financing needs of public pay-as-you-go pension schemes. Better fiscal accounting would provide more discipline by the financial markets.

The countries adopting the Debt Sustainability Pact would be required to submit a medium-term programme indicating a 5-year target for the debt ratio, which would represent the benchmark for assessing their results. They would have greater flexibility in the short term. The focus of EU monitoring would shift from the year-by-year monitoring of the deficit to a medium-term perspective based on long-term fiscal sustainability.

This proposal, however, is also somewhat problematic. First, although targets for the debt ratio may install incentives for governments in the long term, there may be some room for manipulation, by, for example, sale-and-lease-back constructions. Moreover, the proposal is built on the assumption that

\footnotetext{
${ }^{5}$ See also Coeré and Pisani-Ferry (2003). Gros (2003) proposes setting a debt target for each country coupled with a commitment to reduce the distance between their existing debt ratio and that target by one-twentieth each year.
} 
deficits do not matter in EMU if debt levels are under control. This, however, is doubtful, especially from a policy-mix standpoint. Second, while greater reference to the debt ratio does not raise measurement problems, reference to implicit liabilities is more problematic. Estimates are subject to considerable uncertainty related to the macroeconomic, demographic, and behavioural scenarios.

None the less, disregard of the issue of public debt is a clear limitation of the SGP. As argued below, this dimension could be reintegrated without overhauling the current fiscal rules.

\section{REVISITING THE SGP: WORKABLE IMPROVEMENTS}

\section{(i) Lessons from the Debate}

Each of the proposals examined above draws attention to one or more potentially serious problems with the design and implementation of the SGP. The suggestion of implementing institutional and procedural reform highlights the need for an independent enforcer. The idea of moving to a golden rule stresses the need to preserve the growth aspect of the SGP. A number of proposals highlight the excessive uniformity of the current rules. Taking into account the different levels of public debt points to the need to insert the sustainability dimension into the core of the SGP. The idea of an aggregate stability programme highlights the need to take into account the euro-area dimension when assessing national budgetary policies. The proposal for establishing a market for deficit permits tackles the problem of the pro-cyclical bias in good times.

However, none of the proposals put forward in the literature represents a Pareto improvement. While appropriate to some of the problems highlighted in the debate, none of them solves all problems, and each may even aggravate some of them. Also, 'firstbest' solutions at the national level may end up being 'third best' when transposed to a supra-national context. Finally, from a political perspective, attempting to rewrite the rules from scratch may lead to a vacuum in which the current rules are suspended while none of the alternative options is supported by a sufficiently large political constituency.
Our analysis of the SGP against desirable rules standards for design and compliance shows that the current EU fiscal rules fare reasonably well, especially if account is taken of their multinational character. None the less, improvements can be achieved. In our view, key aspects are allowing a certain country-specificity, re-balancing their sticks and carrots, and enhancing enforcement mechanisms.

\section{(ii) A Pragmatic Way Forward}

Our proposal involves a diversification of the medium-term targets, higher transparency and better monitoring, mechanisms to correct misbehaviour in good times, and a non-partisan application of the rules.

A country-by-country articulation of the medium-term budgetary target

The close-to-balance rule interpreted as broadly balanced budgets in cyclically adjusted terms may lead to excessive uniformity between countries. It treats equally countries with different debt levels, contingent liabilities, and public-investment needs. So far, countries are only differentiated in the variability of the cyclical component of the budget balance: economies subject to higher business-cycle volatility and having larger automatic stabilizers require a larger cyclical safety margin in order to avoid breaching the 3 per cent of GDP deficit ceiling under normal cyclical circumstances (EC, 2002a).

The articulation of the medium-term budgetary targets could be extended to $(a)$ the financial fragility of the country embodied in its stock of public debt and $(b)$ the threat to long-term sustainability given by the implicit liabilities of pension systems.

Countries with a relatively low stock of debt-i.e. well below the 60 per cent of GDP reference value - and with relatively low estimated contingent liabilities, could be allowed to have cyclically adjusted budget deficits up to their minimal benchmarks. This solution would be consistent, in most cases, with a prudent version of the golden rule.

Commonly agreed estimates of contingent liabilities in EU countries would have to be computed. Countries would have to provide transparent projections on a regular basis. ${ }^{6}$ The possibility of having a small

\footnotetext{
${ }^{6}$ It would also be useful to attribute the responsibility for projections to independent authorities or to competing institutions (see Franco and Marino, 2002).
} 
structural deficit could be limited to the countries for which expenditure trends do not imply a debt level rising above the 60 per cent threshold over a certain period of time.

The debt ratio in high-debt countries and in countries with expected rising expenditure levels would decline fast, thereby contributing to offset the burden of ageing in the future, while in the other countries deficit levels would ensure the maintenance of a small public debt.

\section{Improving transparency}

An effort should be devoted to enhancing transparency in current and prospective fiscal accounts. In general, transparency can increase the credibility of rules by allowing a better judgement of fiscal performance and by limiting the role of accounting creativity in meeting targets.

The current EMU fiscal framework has been criticized for lack of transparency. This issue has different facets. First, in order to meet the shortterm targets, countries have frequently adopted one-off, cash-raising measures instead of making the necessary structural adjustment. Second, under the current system of national accounts, monitoring is hampered by delays in data provision, with the implication that the whistle is often blown far too late. Third, data on off-budget liabilities and budgetary prospects have generally been rather limited.

To remedy the first problem, the Commission suggested that compliance with the EU rules should distinguish between long-lasting and one-off measures (EC, 2002b). Given the current legislation and accounting conventions, the 3 per cent rule cannot be modified to allay this concern. However, in evaluating fiscal positions, the existence of temporary measures should be considered.

The problem of early detection of deviations from targets was vividly exposed in the case of Portugal in 2001. Moreover, one can see that public-debt growth has frequently exceeded the deficit level. Stock-flow effects have systematically contributed to debt growth. A way to tackle this issue is to resurrect, in parallel with national accounts definitions, regular monitoring of cash flows (Balassone et al., 2002). National authorities would be required to indicate ex-ante cash figures broadly consistent with the European system of national accounts (ESA95) balance. Alternatively, changes in the debt level (net of the effects of exchange-rate changes and privatization proceeds) could be monitored. If a significant departure from target is detected in financial flows, it would be up to them to explain this difference.

Finally, on the basis of an agreed and transparent framework, governments could be required to provide estimates of off-budget liabilities, of their net asset position, and of long-term budgetary trends. Estimates should be revised every year. Changes should be explained.

\section{Tackling misbehaviour in good time}

It is widely recognized that the SGP does not provide sufficient incentives for countries to run prudent fiscal policies in good times. Within the boundaries of the current rules, a two-pronged approach could be the following: first, devise a sanction to punish early slippages in good times and, second, make it easier for countries to behave prudently in periods of upturn.

In order to step up peer pressure, a possible solution could be that of using the early warning procedure of the SGP not only in bad times, when the deficit approaches the 3 per cent ceiling, but also in good times when a significant divergence from structural targets is detected.

The introduction of rainy-day funds may improve policies in good times. These are reserve funds that would be used in times of recession and replenished in upturns. Rainy-day funds are used by several US states and Canadian provinces to buffer the effects of unexpected negative events and cyclical downturns (Knight and Levinson, 1999). These funds might increase the incentive for governments not to waste the surpluses in good times and increase the room for manoeuvre in bad times. They would also increase the role of public budgets in stabilizing the economy over the cycle. The possibility of accumulating such funds could be made a function of the country's level of public debt. For instance, it could be open only to countries with a stock of debt below a certain debt threshold, and the allowed maximum size of accumulated funds could be increased the lower the stock of debt. This would de-facto make the deficit ceiling a negative function of the debt ratio. 
The establishment of rainy-day funds would imply a review of the current ESA accounting rules for calculating budgetary indicators. Transfers of resources to and withdrawals from the fund would now be considered financial operations (below the line) and hence deficit-neutral. A revised interpretation should establish that transfer of resources to the fund in good times reduces the budget surplus, while withdrawal from the fund in bad times is considered as additional revenue and thus reduces the deficit. There should be some rule to ensure that rainy-day funds are used only in recessions.

The possibility of establishing rainy-day funds would not obviously tackle at the root the incentive problem that governments have in good times. However, the flexibility that they would provide would allow a tightening of sanctioning procedures for countries exceeding the 3 per cent limit. For instance, the payment of the non-interest-bearing deposit could be accelerated and the closeness clause (the amount by which the 3 per cent limit can be exceeded) could be defined in a strict way.

\section{Non-partisan implementation of the rules}

A strong criticism of EMU rules is that enforcement is partisan: national authorities are supposed to apply the rules to themselves, thereby having incentives for collusion and horse-trading.

In order to move to a non-partisan implementation of the rules, one has to distinguish between three types of decisions which need to be taken in the implementation of the SGP: (a) technical decisions on the compliance with the rules; $(b)$ political decisions on measures to be taken to prevent or correct an excessive deficit; $(c)$ implementation of sanctions.

The Commission should be entrusted with the implementation of decision $(a)$. It should be entitled to deliver the first early warning, and to determine the existence of an excessive deficit. The Commission, without requiring approval by the Council, would also assess whether exceptional circumstances apply.

The Council should take decision $(b)$ on the measures to be implemented to correct the fiscal imbalance. Hence, the Council should decide on the second early warning which requires the specifica- tion of the corrective measures. As prescribed by current rules, the decision would be taken by the Council on a qualified majority basis following a recommendation by the Commission.

Decision (c), on the application of sanctions, is of both a technical and a political nature. Leaving it exclusively to the Commission would be unthinkable. A solution that would reduce the risk of a partisan (non-) application of sanctions would be to move from a Commission recommendation to a Commission proposal. The difference is that the Council can move away from the Commission proposal only with unanimity and not with qualified majority as in the case of a Commission recommendation.

These changes are consistent with the spirit of the current rules. However, in order to be implemented fully, a change in the Treaty would be required. If agreement on the principle is achieved, this could be enshrined in a European Council resolution which would state that, in the case of the technical decisions, the Council commits itself to rejecting the Commission recommendations only with unanimity. The crucial question is, of course, whether or not the Council is prepared to strengthen the authority of the Commission in the interest of the credibility of EU fiscal rules.

\section{CONCLUSIONS}

The SGP's aim is to balance fiscal discipline and fiscal stabilization in a multinational context in which countries ultimately remain responsible for fiscal policy. It tries to combine some flexibility for exceptional events with a need for predefining the necessary room for manoeuvre to smooth the business cycle.

While the Pact presents some drawbacks-particularly in terms of investment financing, asymmetric incentives, and lack of a long-term view-it is not evident that any alternative would be preferable on every account. Most of the benefits of alternative rules can be attained by an appropriate interpretation of the SGP provisions which would diversify countries' fiscal commitments according to their specific economic and public-finance features. 
Our basic tenet is that there are no miracle solutions to cure the Pact's weaknesses. Changes might obviously regard the specific values of the parameters, but not the underlying philosophy-that is, setting a prudent budgetary objective in normal times and a deficit ceiling in bad times.

Only 4 years into EMU, any radical change would be highly problematic from a political standpoint. The obvious risk is that of ending up in a vacuum in which the old rules are called into question while the agreement on a new set of rules fails to materialize. Venturing into an EMU without fiscal rules would be a leap in the dark. At the same time, given the current level of political integration, the conditions for a federal system of public finances do not seem to exist.

While we are sceptical of re-opening the debate on the SGP, we think that its functioning can none the less be improved. Our main proposals concern redefining the medium-term budgetary targets, improving transparency, tackling the pro-cyclical fiscal bias in good times, moving towards non-partisan application of the rules, and improving transparency in the data. This set of ideas can allow the achievement of both stronger discipline and higher flexibility and can be implemented without requiring any major revision of the existing rules. An assessment of the aggregate fiscal position prior to the evaluation of the individual national policies can also be considered. It may help to achieve a coherent fiscal stance at the euro-area level, but it should not weaken the current framework.

These proposals do not provide a recipe for tackling the problems encountered by countries still in transition towards lower deficits in the event of a cyclical slump. Nevertheless, if implemented, they would limit the type of behaviour which is largely responsible for the current fiscal tensions.

\section{REFERENCES}

Artis, M. J. (2002), 'The Stability and Growth Pact: Fiscal Policy in the EMU', in F. Breuss, G. Fink, and S. Griller (eds), Institutional, Legal and Economic Aspects of the EMU, Wien-New York, Springer.

Balassone, F., and Franco, D. (2000), 'Public Investment, the Stability Pact and the Golden Rule', Fiscal Studies, 21(2), 207-29.

— _ - (2001), 'EMU Fiscal Rules: A New Answer to an Old Question?', in Banca d'Italia (2001), 33-58.

— Z Zotteri, S. (2002), 'Fiscal Rules: Indicators and Underlying Statistical Frameworks', Banca d'Italia, mimeo.

Banca d'Italia(2001), Fiscal Rules, Rome, Banca d'Italia.

Blanchard, O. J., and Giavazzi, F. (2003), 'Reforms that Can be Done: Improving the SGP through a Proper Accounting of Public Investment', MIT, mimeo.

Brunila, A., Buti, M., and Franco, D. (eds) (2001), The Stability and Growth Pact-The Architecture of Fiscal Policy in EMU, Basingstoke, Palgrave.

Buiter, W. H. (2001), 'Notes on a "Code for Fiscal Stability"', Oxford Economic Papers, 53(1), 1-19.

- Grafe, C.(2003), 'Reforming EMU's Fiscal Policy Rules—Some Suggestions for Enhancing Fiscal Sustainability and Macroeconomic Stability in an Enlarged European Union', in M. Buti (ed.), Monetary and Fiscal Policies in EMU: Interactions and Coordination, Cambridge, Cambridge University Press, forthcoming.

Buti, M., and Martinot, B. (2000), 'Open Issues in the Implementation of the Stability and Growth Pact', National Institute Economic Review, 174, October, 92-104.

- Nava, M.(2003), 'Towards a European Budgetary System', paper prepared for the annual congress of the IIPF, Prague, August.

- Eijffinger, S., and Franco, D. (2003), 'Revisiting the Stability and Growth Pact: Grand Design or Internal Adjustment?', CEPR Discussion Paper 3692.

- Franco, D., and Ongena, H. (1998), 'Fiscal Discipline and Flexibility in EMU: The Implementation of the Stability and Growth Pact', Oxford Review of Economic Policy, 14(3), 81-97.

Calmfors, L., and Corsetti, G. (2002), 'How to Reform Europe's Fiscal Policy Framework', WorldEconomics, 4(1), 109-16. Casella, A. (2001), ‘Tradable Deficit Permits', in Brunila et al.(2001), 394-413.

Coeré, B., and Pisani-Ferry, J. (2003), ‘A Sustainability Pact for the Eurozone', paper presented at HM Treasury’s 'Keynes Seminar', February. 
de la Fuente, A. (1997), 'Fiscal Policy and Growth in the OECD', CEPR Discussion Paper 1755.

EC (2002a), 'Public Finances in EMU-2002', European Economy, 3, European Commission.

- (2002b), 'Strengthening the Coordination of Budgetary Policies', COM (2002) 668, November, European Commission.

EEAG (2003), Report on the European Economy 2003, Munich, European Economic Advisory Group at CES Ifo, February.

Franco, D., and Marino, M. R. (2002), 'The Role of Forecasts in Social Security Policy', Giornale degli economisti, forthcoming.

Gros, D. (2003), 'A Stability Pact for Public Debt?', CEPS Policy Brief 30, January.

HM Treasury (1998), The Code for Fiscal Stability, November, London, HM Treasury.

Inman, R. P. (1996), ‘Do Balanced Budget Rules Work? US Experience and Possible Lessons for the EMU', NBER Working Paper Series 5838.

Kilpatrick, A. (2001), 'Transparent Frameworks, Fiscal Rules and Policy-making Under Uncertainty', in Banca d'Italia (2001), 171-216.

Knight, B., and Levinson, A. (1999), 'Rainy Day Funds and State Government Savings', National Tax Journal, 52(3), 459-72.

Kopits, G., and Symansky, S. (1998), 'Fiscal Policy Rules', IMF Occasional Paper 162.

Musgrave, R. A. (1939), 'The Nature of Budgetary Balance and the Case for a Capital Budget', American Economic Review, 29, 260-71.

Pench,L.R.(2003), 'Comment on Buiter and Grafe', in M. Buti(ed.), Monetaryand Fiscal Policies in EMU: Interactions and Coordination, Cambridge, Cambridge University Press, forthcoming.

Pisani-Ferry, J. (2002), 'Fiscal Discipline and Policy Coordination in the Eurozone: Assessment and Proposals', paper prepared for the Group of Economic Analysis of the European Commission, April.

Razin, A., and Sadka, E. (2002), 'The Stability and Growth Pact as an Impediment to Privatizing Social Security', CEPR Discussion Paper 3621.

Wendorff, K. (2001), ‘The Discussion of a National Stability Pact in Germany', in Banca d'Italia (2001), 677-712.

Wyplosz C. (2002), 'Fiscal Policy: Rules or Institutions?', paper prepared for the Group of Economic Analysis of the European Commission, April. 